\title{
A possible mechanism for accidental humeral fractures in infants
}

\author{
Carole Jenny
}

Received: 16 May 2014 / Accepted: 18 June 2014 / Published online: 2 August 2014

(C) Springer-Verlag Berlin Heidelberg 2014

In their paper, "Humeral fracture in non-ambulant infants - a possible accidental mechanism," Somers, Halliday and Chapman [1] present a challenging and important concept for fracture generation. In their seven cases, non-mobile infants are described as possibly breaking their humeri while rolling over. The authors make the argument that the infants rolled on an outstretched arm.

The most convincing aspect of their explanation involves infants' developmental status. When just starting to roll, infants get to their sides and then "flop over" in an uncontrolled movement. They have minimal strength in their backs and abdominal muscles, so potentially they could be unable to stop the movement of their trunks once they are in a lateral position with the trunk perpendicular to the bed surface. As the authors point out, this is much more credible when an infant is prone rolling supine rather than the opposite. From supine to prone, it is harder to picture a fulcrum developing to apply force to the mid-shaft of the bone.

Adding to the dilemma is the absence of knowledge on infant bone biomechanics. We do not know exactly how much force is required to fracture the average infant's humerus, nor do we know the range of normal bone strength in healthy infants. We do not yet have an adequate model for investigating bone strength in infants, and infant cadaver specimens are rarely made available to researchers [2].

This is why it is so difficult to make the final diagnosis in an injured infant. On the one hand, sending a baby back to an abusive environment puts the child at risk of further injury or even death. On the other hand, intervening unnecessarily in a caring family can cause damage to both parents and their infants. The problem is complicated by the fact that infant

C. Jenny $(\bowtie)$

Seattle Children's Hospital,

University of Washington School of Medicine,

M/S M110 4800 Sand Point Way,

Seattle 98105 , WA, USA

e-mail: cjenny@uw.edu caretakers are not always honest and reliable when describing injury mechanisms in the children. The authors' thoughtful, balanced discussion of these cases is refreshing and shows that experts in the fields of pediatric radiology and child abuse pediatrics can be objective and open-minded. They do not necessarily rush to judgment when analyzing tough cases.

I am reminded of a recent case in which a young infant sustained an unexplained spiral fracture of the humerus. After a thorough medical evaluation, Child Protective Services investigated the case and decided that the baby was safe to go home with his parents, who appeared loving and appropriate. A few weeks later the infant sustained a lifethreatening head injury that left him severely and permanently handicapped and completely dependent on others for care. Nevertheless, these nightmare scenarios should not keep us from being open to credible theories of accidental causation. No field of medicine can be $100 \%$ certain when making a diagnosis in some cases, including the diagnosis of child abuse.

The authors of this paper have made an important contribution to the literature on infant fractures that should remind us of the importance of open-minded scientific discourse.

Conflicts of interest None

\section{References}

1. Somers JM, Halliday KE, Chapman S et al (2014) Humeral fracture in non-ambulant infants - a possible accidental mechanism. Pediatr Radiol doi:10.1007/s00247-014-2954-8

2. Pierce MC, Bertocci GE, Vogeley E et al (2004) Evaluating long bone fractures in children: a biomechanical approach with illustrative cases. Child Abuse Negl 28:505-524 